\title{
Methodology to Detect and Isolate Water Losses in Water Hydraulic Networks: Application to Barcelona Water Network
}

\author{
Joseba Quevedo*, Ramon Pérez*, Josep Pascual*, Vicenç Puig*, \\ Gabriela Cembrano $^{* / * * *}$ and Antonio Peralta ${ }^{* *}$ \\ * Automatic Control Department and Institut de Robòtica i Informàtica Industrial \\ Technical University of Catalonia (UPC) and Spanish Research Council (CSIC), \\ Rambla Sant Nebridi, 10, 08222 Terrassa, Barcelona, Spain \\ (e-mail: joseba.quevedo@upc.edu)
}

**Sociedad General de Aguas de Barcelona (AGBAR), C/. General Batet, 1-7, 08028 Barcelona, Spain.

*** Water Technology Centre (CETaqua), C/. Esplugues 75, 08940 Cornellà de Llobregat, Spain.

\begin{abstract}
This paper presents a methodology to detect real water losses in urban water networks. The proposed method is based on the combined use of the DMA economical water balance confidence intervals for a period of time longer than a month (a trimester, semester or year) with appropriated night flow ratio intervals. This method allows distinguishing between real and apparent water losses in a given DMA. The use of uncertainty models allows taking into account measurement uncertainty of the flow data sensors. The use of different periods of time allows the stabilization of the results. This methodology is illustrated in a DMA of the Barcelona water distribution network using real data.
\end{abstract}

Keywords: Fault detection and isolation, Leak detection, Water systems, DMA, Confidence intervals.

\section{INTRODUCTION}

An important matter concerning water distribution networks is system water loss, which has a meaningful effect on both water resource savings and costs of operation (Farley and Trow, 2003). The International Water Association (IWA) founded the IWA Water Loss Task Force to coordinate and disseminate contributions to improve the water loss management and to elaborate procedures, standard terminology and recommend performance measures based on the components of any water network. For modern water loss management of large water distribution networks there is two sequential procedures:

- Methodologies and techniques to detect and identify the sectors or areas of the network where probably are situated the most important water lost of the network, considering all types of leaks, bursts and overflows.

- Methodologies and techniques to identify the lost water in the pipelines and to precise the location of leakages in the pipelines

This work is focused on the first procedures of water loss management to detect and isolate the loss water in the DMA of a large water distribution network.

Several authors propose the use of hydraulic models to detect leaks in water networks (Almandoz, 2005; Wu, 2006; Perez, 2010). Lambert (1994) proposed to combine the annual balance of water networks of German Water Companies with the study of night water consumption used by Britannic Water Companies to estimate which sectors of the network are more liable to suffer real water losses or apparent losses due to metering underestimation errors. The standard balance of water from IWA (Lambert, 1994) is very useful for this task. The concept of Non-Revenue Water (NRW) includes (Table 1) all measured or non- authorized consumptions of water and the water losses. Two specific items were defined within the generic water losses: the apparent losses, where the non authorized consumptions are included such as fraud and consumer metering inaccuracies and the real losses which take into account the leakage on transmissions and distribution mains, leakages and overflows in the storage tanks and the leakages on the service connections up to points of the consumer metering.

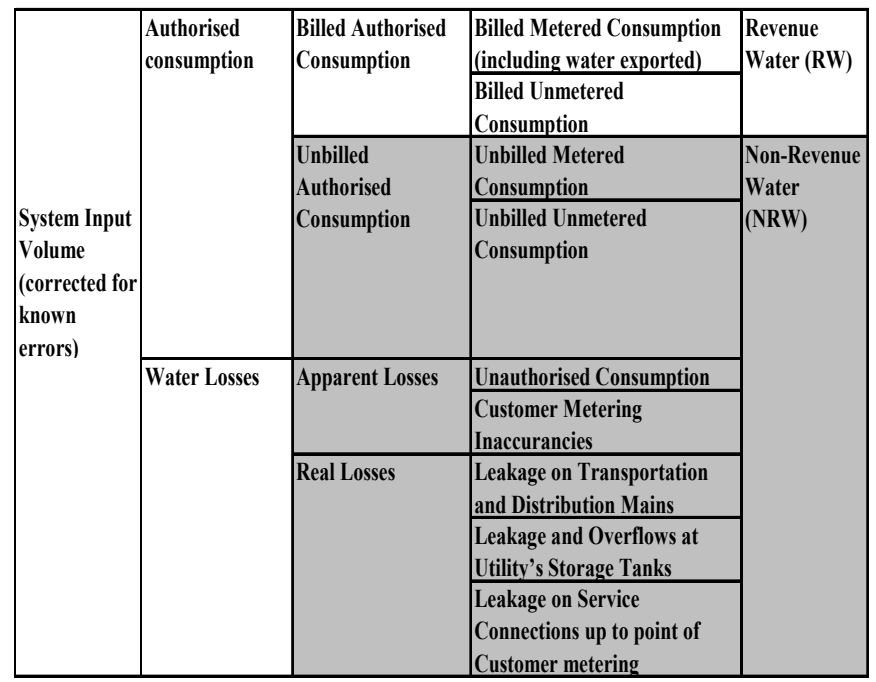

Table 1. Standard balance of water from International Water Association (Lambert, 1994) 
Many performance indicators can be used to analyse the results of different sectors of a large distribution network and take decisions about the management (maintenance, operation, instrumentation,...) plans of the whole network. Since the early 1980's it has been recognised that percentages are unsuitable for assessing the operational efficiency of management of real losses (leakage and overflows) in distribution systems. This is because the calculated percentages are strongly influenced by the consumption of water in each individual system, and variations in that consumption. Non-Revenue Water expressed as a percentual by volume of Water Supplied, although traditionally widely used, also suffers from similar significant problems to Real Losses percentual when used as a Performance Indicator. The Financial Performance Indicator (Lambert, 2000) overcomes this problem by converting components of NRW into money, using appropriate valuations, and expressing NRW value as a $\%$ of system running costs.

On the other hand, the first IWA Water Loss Task Force developed and published (Lambert, 2000), the following equation for predicting the UARL (Unavoilable Annual Real Losses in liters/day) for well-maintained systems with infrastructure in good condition:

$$
\mathrm{UARL}=(0.018 \times \mathrm{Lm}+0.8 \times \mathrm{Nc}+0.025 \times \mathrm{Lp}) \times \mathrm{P}
$$

where $\mathrm{P}$ is the average system pressure in meters, $\mathrm{Lm}$ is the mains length $(\mathrm{m}), \mathrm{Nc}$ is the number of service connections and $\mathrm{Lp}$ is total length of private pipe, property line to customer meter $(\mathrm{m})$.

This equation has proved to be robust when applied internationally since 1999; although some water suppliers have achieved these levels of Real Losses, very few have been able to consistently achieve validated lower levels of Real Losses. The UARL is used to calculate the Infrastructure Leakage Index (ILI), a non-dimensional performance indicator for operational management of Real Losses. The ILI is the ratio of the Current Annual Real Losses to the system-specific Unavoidable Annual Real Losses (calculated from the above equation for UARL).

Measurements of night flows into sectors of the distribution network are also extremely useful for rapidly detecting and isolating the presence of new unreported leaks in the network, which can then activate a more detailed plan to determine exactly the location of the leakage using other complementary techniques (acoustic equipments, correlation methods, robots and vision systems,...). These last techniques are not the object of this paper.

This paper presents in the section 2 the methodology used by AGBAR Company to detect and isolate the suspicious sectors to have the main leakages of the network which will be illustrated with a real sector of Barcelona network. The problems of this methodology will be overcome proposing an interval model to represent the time series data of the flowmeters as a previous step to compute an interval economical water balance of the DMA in section 3. Section 4 shows the results obtained in a DMA of the Barcelona water network and the main conclusions are described in Section 5.

\section{PROBLEM FORMULATION}

\subsection{Current procedure}

Barcelona water network methodology is based on the decomposition of the large network of the city into several areas (DMA: district-metered areas) where the supplied and transferred volumes are easily metered. This decomposition makes it possible to perform more detailed water economical balance calculations and, therefore, to monitor the networks more efficiently.

The basic idea of this methodology is to combine analysis month by month in two ratios: the economical balance, as the ratio of billed volume respect to the supplied volume of each DMA, and the monthly mean night consumption respect to reference night consumption for each DMA. This combined information (figure 1) of the whole network can be useful to distinguish and isolate the DMA(s) with real losses from those with apparent losses (metering underestimation or frauds) or without losses.

Figure 1 shows how works the combination of these two indicators (Peralta, 2005) and which divide the 2D space in 4 classes, and each class shows the most likely symptoms and actions to be taken.

\section{Classification of DMA and the most probably}

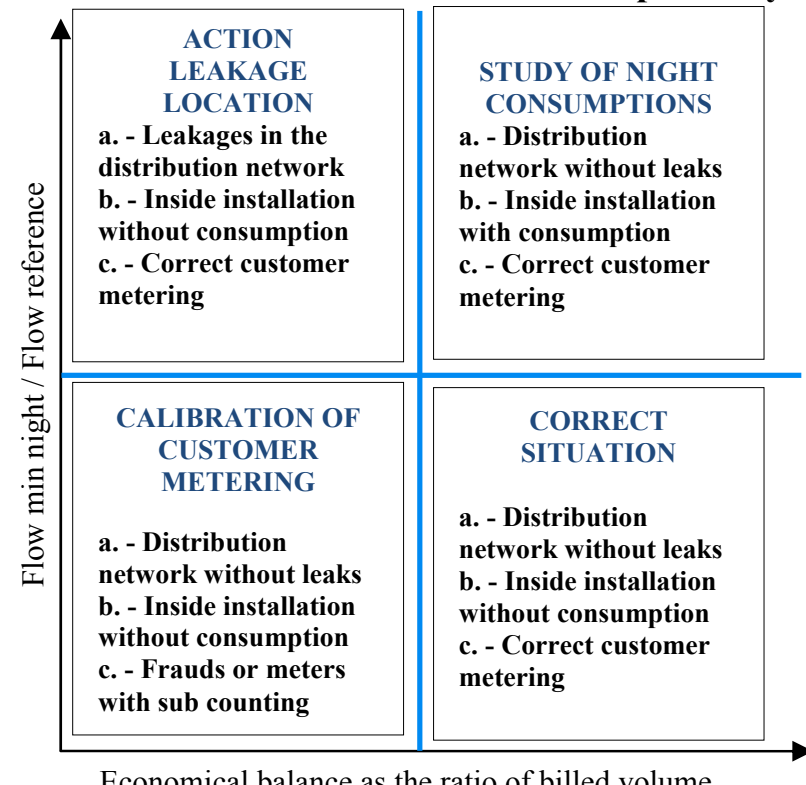

Economical balance as the ratio of billed volume respect to the supplied volume

Fig. 1. Combined Analysis of Economical Water Balance and night consumption of DMA's

The economical water balance is the ratio of supplied and registered volumes for a given period of time (month, trimester):

$$
\eta_{\text {econ }}=\frac{\text { billed volume }}{\text { supplied volume }}
$$


The mean minimum night flow is the arithmetic mean value of the measured in a short period of time (i.e. from $0 \mathrm{~h}$ to $4 \mathrm{~h}$ am everyday) during all the days of the studied month and the night reference flow $(1 / \mathrm{s})$ can be computed as proposed by Lambert (1994) through the following expression:

$N F N=\left(\left(0.035 \cdot L+2.5 \cdot N_{a}\right) \cdot P C F+1.5 \cdot N_{s}\right) \cdot \frac{S C F}{3600}$ where

- $\quad L$ : length of the network in meters.

- $\quad P C F$ is a corrective factor of the average night pressure in the network, which is equal to one if the pressure is 40 meters, computed as:

$P C F=\frac{0.5 \cdot P_{\text {average }}+0.0042 \cdot P_{\text {average }}^{2}}{0.5 \cdot 40+0.0042 \cdot 40^{2}}$

- $S C F$ is corrective factor of the sampling time, computed as:

$$
S C F=\frac{1}{0.95+\frac{360}{3600+S}}
$$

where $S$ is the sampling time in seconds. For 600

seconds SCF is equal to 0.966 .

- $\quad N_{a}$ is the number of connections.

- $\quad N_{s}$ is the number of customer suppliers.

The plot in Figure 1 gives useful information to the responsible of the network operation for each sector or DMA of the water distribution network. It helps in the maintenance planning to minimise water loss in the network and to locate the non visible leakages in those DMA that appear prone to have leakages. Indeed, a low economical water balance of the DMA combined with a high ratio of night consumption indicates the existence of real leakages, and a low economical water balance combined with low night consumption, close to the reference seems to indicate a sub counting of the customer metering or a non authorised consumption. However, an economical water balance close one, combined with a high ratio of night consumption indicates that there are no leakages but high water consumption due to any activity (industrial or commercial). And, finally, if the water economical balance is close to one and the night consumption is close to the reference value then the operation of this sector or DMA is suitable without leakages and with the customer metering working properly.

\subsection{Network diagnosis today}

This above-described analysis is regularly applied in Barcelona water distribution network by the AGBAR Company for the complete set of the DMA every month.

To illustrate this analysis, some results obtained in the past year are presented in this section. This analysis shows the monthly results of one DMA of Barcelona water network, Plaça del Diamant. The data used for this study are:

- Supplied and registered volumes every month for the DMA.

- Mean monthly minimum flow of the DMA with a sampling time of 10 minutes.

\section{- $\quad$ Reference flow for the DMA.}

Figure 2 shows the historic data of monthly supplied and consumed volumes of Plaça del Diamant DMA for all of 2007 and Figure 3 shows the evolution of the monthly water economical balance for the same year.

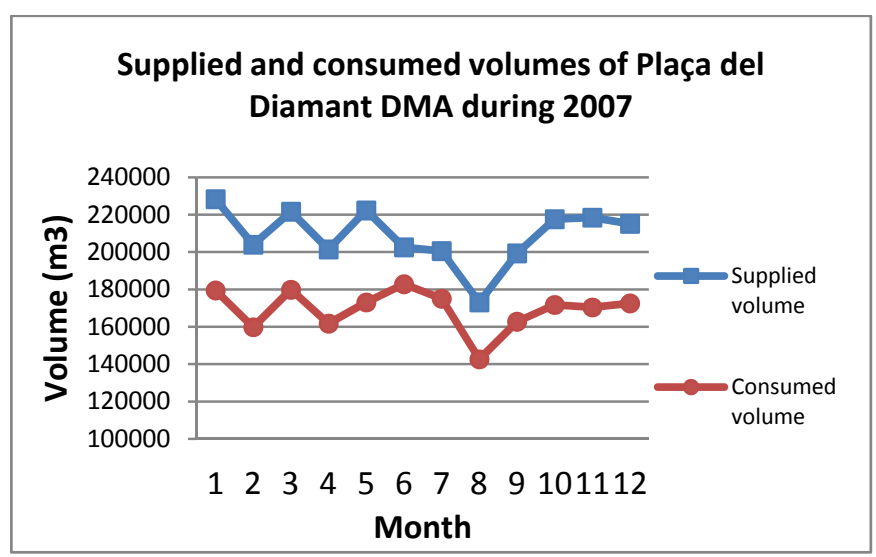

Fig. 2. Supplied and consumed volumes of Pl del Diamant

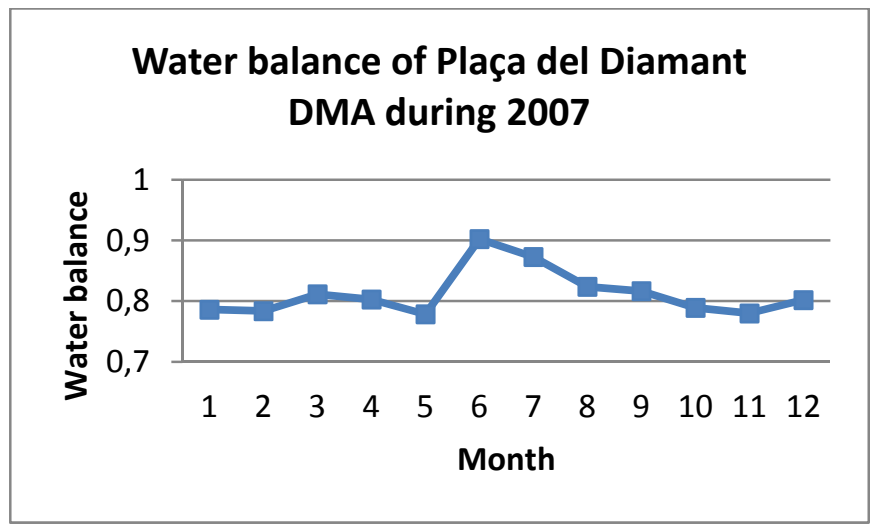

Fig. 3. Economical water balance of Plaça del Diamant

Figure 4 shows the monthly evolution of the combined information of economical water balance and night flow ratio during 2007. Empirically in the Barcelona network the thresholds for high and low balance has been predefined to $0.8(80 \%)$ and the high and low night flow ratio to 2 times.

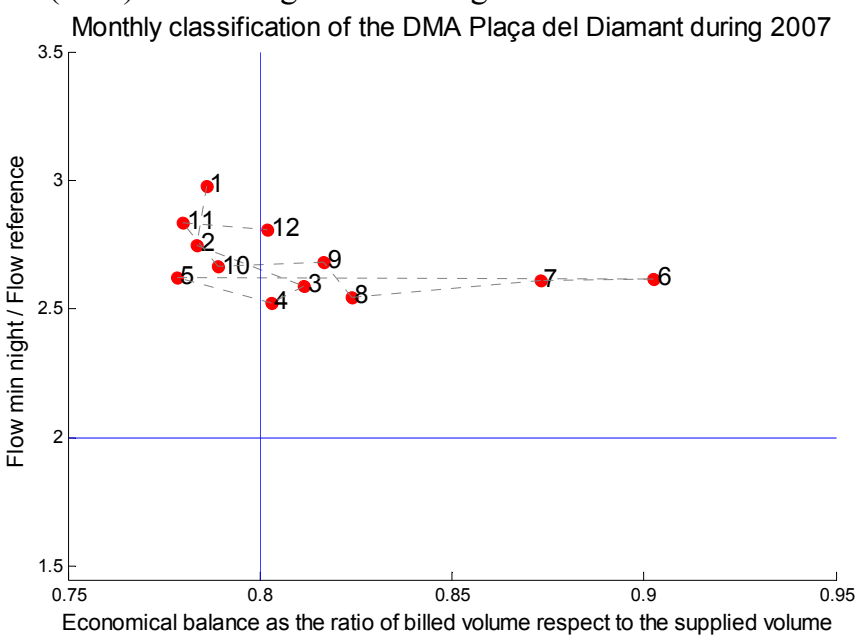

Fig. 4. Economical water balance related to normalized minimum flow in Plaça del Diamant DMA during 2007 
The legend $1,2,3, \ldots$ of this figure correspond to the number of the month in the year (January, February, March,...). If the graphical results of Figure 4 are translated into a string of monthly diagnosis for Plaça del Diamant DMA, Table 2 is obtained. Five months suggest that this DMA has real losses and actions are proposed to locate leaks. The rest of the year, the diagnosis shows (7 months) this DMA to have only big night consumption.

This confusing diagnosis makes it hard to achieve the water loss reduction decision plan for this DMA. Similar results are obtained for other DMA in the Barcelona network.

\begin{tabular}{|ll|}
\hline Month & \multicolumn{1}{c|}{ Diagnosis } \\
\hline January 2007 & Leakage location \\
\hline February 2007 & Leakage location \\
\hline March 2007 & Study of night consumptions \\
\hline April 2007 & Study of night consumptions \\
\hline May 2007 & Leakage location \\
\hline June 2007 & Study of night consumptions \\
\hline July 2007 & Study of night consumptions \\
\hline August 2007 & Study of night consumptions \\
\hline September 2007 & Study of night consumptions \\
\hline October 2007 & Leakage location \\
\hline November 2007 & Leakage location \\
\hline December 2007 & Study of night consumptions \\
\hline
\end{tabular}

Table 2. Monthly diagnosis of Plaça del Diamant in 2007

The origin of this problem is the variability of the monthly economical water balance observed in Figure 4 where depending of the month the economical balance is quite good (0.9 in June 2007) or quite deteriorated (0.77 in May 2007). It's well know that the common practice of expressing Revenue Water or Billed Water as a \% of Volume Supplied is unsuitable for assessment the operational efficiency of management of distribution systems because of differences and changes in the consumptions.

Though it is kept the same procedure, indicators of the figure 1 , it seems more reasonable to apply other that take into account the precision of the flowmeters to compute the real economical balance of the DMA and change the frequency to compute this study from one month to a trimester in order to filter these results. This improved version is presented in the next section.

\section{IMPROVED METHODOLOGY}

The analysis of nominal consumptions, balances and night flows produces a high variability and confusion in the diagnosis of water real losses. In this section, a new approach will be used that takes into account the uncertainty and the noise of the original measurements through confidence intervals.

\subsection{Uncertainty estimation of the consumption sensors}

- The variability of the night consumption is due to two main causes, the first is due to the different daily demand behaviour of the month (probably it is not the same the night consumption of Saturdays or Sundays than the workdays) and secondly due to the noise of the flow meters which measures the low consumption of the each DMA. In order to manage this uncertainty a simple computation of the average and standard deviation of all the daily night consumptions for each month has been done. A confidence interval has been fixed for a given confidence degree parameter ( $\lambda=1.64$ for a confidence of $90 \%, \lambda=2$ for a confidence of $95 \%$ if the measurements error distribution is Gaussian):

$$
\left[\text { night }_{\min }, \text { night }_{\max }\right]=[\text { mean }-\lambda . s t d, \text { mean }+\lambda . s t d]
$$

In order to determine the confidence interval for the economical balance of each DMA of the water network, it is necessary to estimate the sensor precision. The suppliers usually give the precision of the sensors but this performance depends strongly on the operational use of the sensor (speed of the water in a recommended range, minimum distance of the sensor to the pipe elbows,..).

In this analysis, the sensor errors have been estimated from the experimental data of each sensor. The company AGBAR already has a maintenance program to calibrate all the flowmeters of the network once per year and for this reason, systematic errors are not considered in this work.

From the historical daily data of each flowmeter, a timeseries model is generated in order to estimate the flow and to compare with the real data with the aim of quantifying the error between the estimated and real values. A statistical analysis of this error is performed to estimate the standard deviation that will allow determining the random precision of each sensor.

The selected model structure of the time series is:

$\hat{v}(t)=a_{1} \cdot v(t-1)+a_{2} \cdot v(t-2)+\cdots+a_{9} \cdot v(t-9)+$ $a_{10} \cdot v(t-14)$

where $\hat{v}(t)$ and $v(t)$ are, respectively, the estimated and real flow at day $t$. The structure of this time series model takes into account the flows in the previous 9 days and the last term is the flow two weeks earlier ( 14 days). This structure was determined as the best one from trial-error using real data from a big number of flowmeters of the network. The parameters of the time series model of each sensor are estimated using a least-squares method.

\subsection{Confidence interval evaluation of the DMA economical balance}

To evaluate the confidence interval of each DMA economical balance in the assessment of water real loss, three possibilities has been considered:

- Monthly economical balance computation.

- Trimester economical balance computation.

- Semester moving average economical balance computation. 
The confidence interval economical balance is computed using the following expression (Quevedo, 2009):

$$
\left[R_{\text {min }}, R_{\text {max }}\right]=\left[\frac{V_{\text {out }}}{V_{\text {in }}+\lambda \cdot \sqrt{n} \cdot \sigma_{e}}, \frac{V_{\text {out }}}{V_{\text {in }}-\lambda \cdot \sqrt{n} \cdot \sigma_{e}}\right]
$$

where

- $\quad V_{\text {out }}$ is the registered and billed consumed volume.

- $V_{\text {in }}$ is the supplied volume (measured by the flowmeters).

- $\quad \lambda$ is the confidence degree parameter

- $\quad n$ are the number of days considered: $n=30$ for a monthly interval balance, $n=90$ for a trimester interval balance and $n=180$ for a semester.

- $\sigma_{e}$ is the standard deviation between the estimated and the real data.

\subsection{Plaça del Diamant DMA results}

The estimated parameters of the time series model (5), using the well-known least squares method to compute the estimated daily supplied water volume at this DMA, are:

$$
\left(\begin{array}{l}
a_{1} \\
a_{2} \\
a_{3} \\
a_{4} \\
a_{5} \\
a_{6} \\
a_{7} \\
a_{8} \\
a_{10} \\
a_{11}
\end{array}\right)=\left(\begin{array}{c}
0.7648 \\
0.0892 \\
0.0567 \\
-0.0229 \\
0.0378 \\
0.0164 \\
0.0935 \\
-0.2810 \\
0.2716 \\
-0.0261
\end{array}\right)
$$

Figure 6 shows the autocorrelation function of the error between the daily estimation with this time series model and the measured consumptions. The correlation function is always inside the confidence intervals and therefore the residual of this model can be considered.

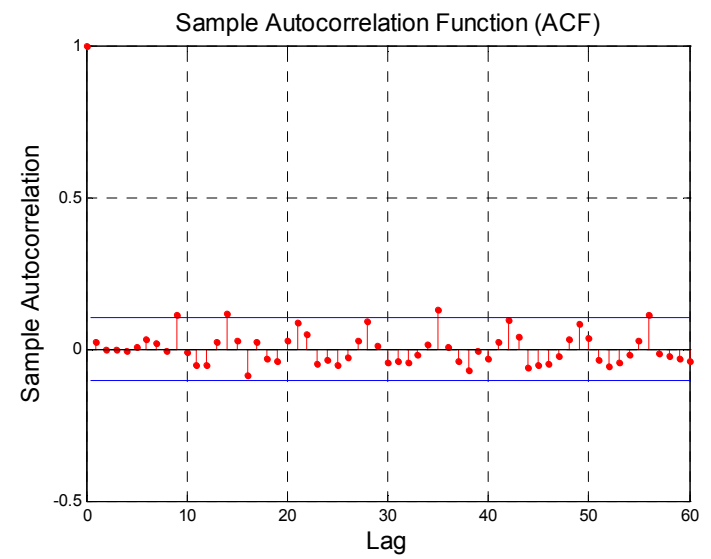

Fig. 6. Validation of the time series model of Plaça del Diamant
The relative error of the daily supplied water is computed by (Quevedo,2009):

$$
\operatorname{error}(\%)=\frac{\lambda \cdot \sigma_{e}}{\bar{V}} \cdot 100
$$

where $\bar{V}$ is the mean volume of water

For a confidence interval of $90 \%(\lambda=1.64)$, the error of the time series model of Plaça del Diamant DMA has been of approximately $9 \%$. This error estimation has been used to compute the confidence interval for the economical water balance (2).

Figure 7 shows the results of the confidences intervals of the monthly night consumptions of Plaça del Diamant DMA and all the intervals are bigger than the prefixed threshold given by AGBAR. Figure 8 shows the same for the economical balance of this DMA and in this case some intervals are bigger and some lower than the prefixed threshold economical balance of 0.8 , but all the upper bounds are bigger than this value and consequently the most probably unique diagnostic for this DMA is more related to a high night consumption than to a leak location.

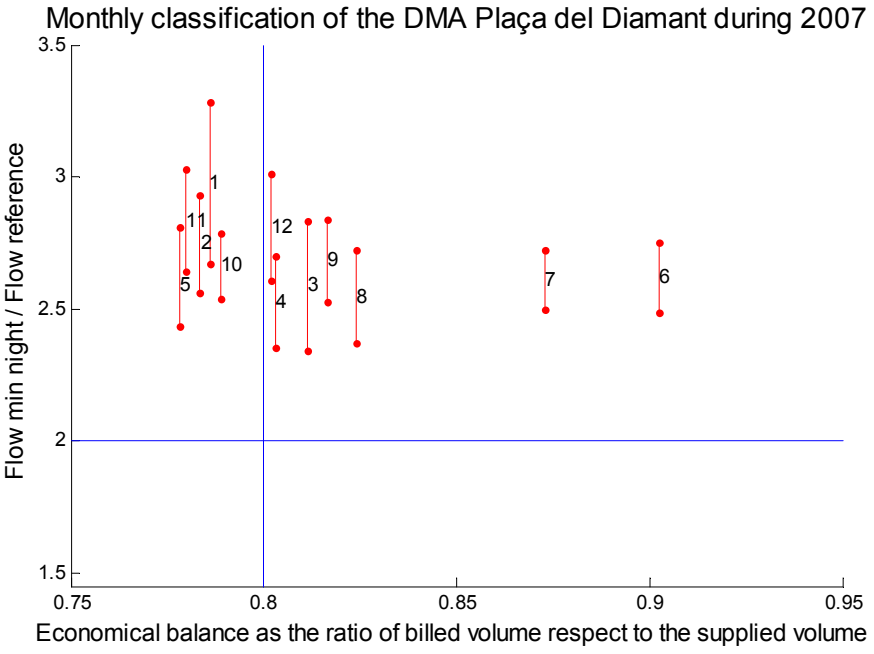

Fig. 7. Results for the monthly water economical balance mean and Qmin/Qref interval for Plaça del Diamant

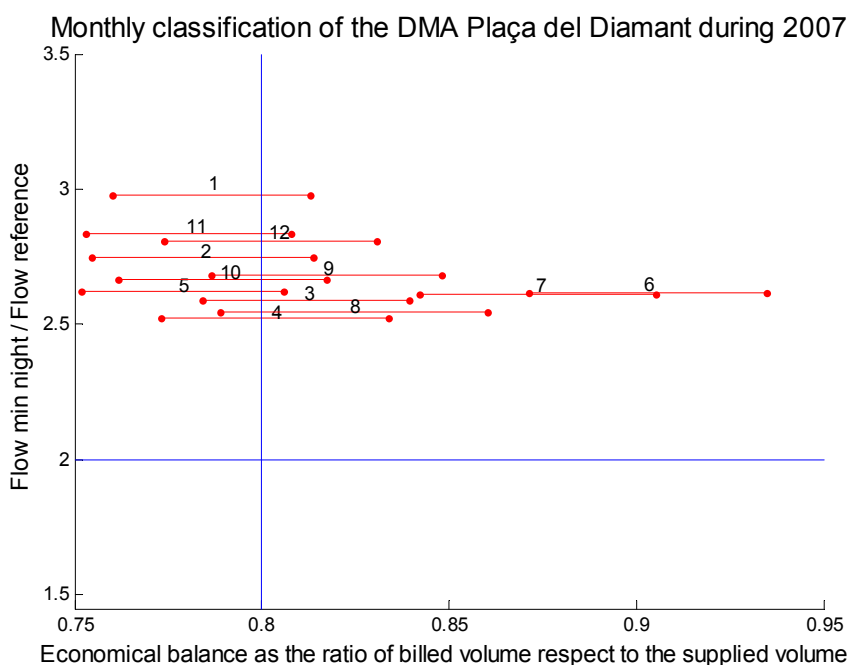

Fig. 8. Results for the monthly water economical balance interval and Qmin/Qref mean for Plaça del Diamant 
To confirm this diagnostic figures 9 and 10 show the results of the trimester and semester moving average interval economical balance respectively versus the same period of interval night flows. Figure 9 presents 4 boxes corresponding to the trimester interval economical balances versus night consumptions intervals. From this figure, the existence of high night consumptions in all the trimester and not real water losses, it can be noticed. Finally, Figure 10, that presents 7 boxes corresponding to the semester confidence interval economical balances versus night consumptions interval, confirms clearly the same diagnostic.

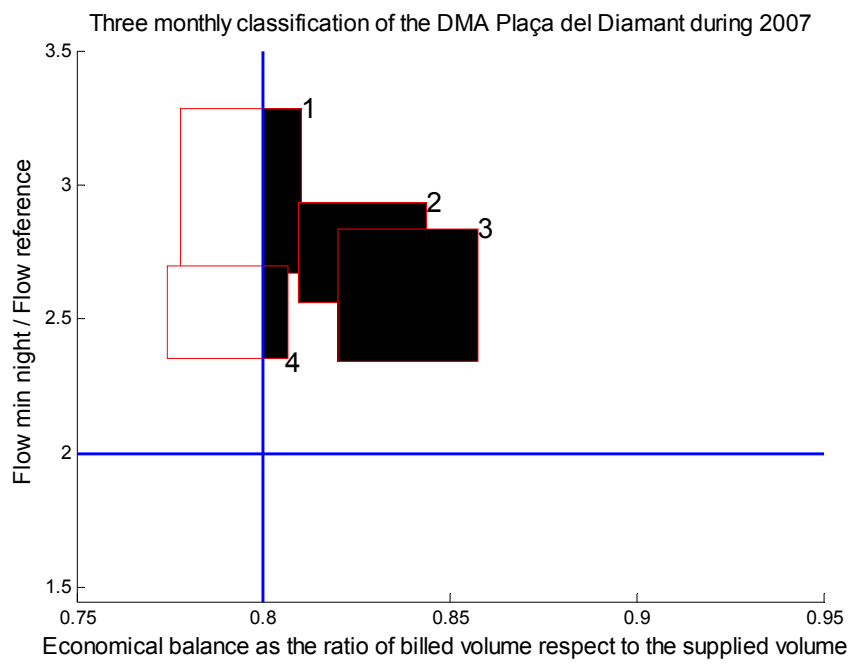

Fig. 9. Results for the three monthly water economical balance and Qmin/Qref for Plaça del Diamant.

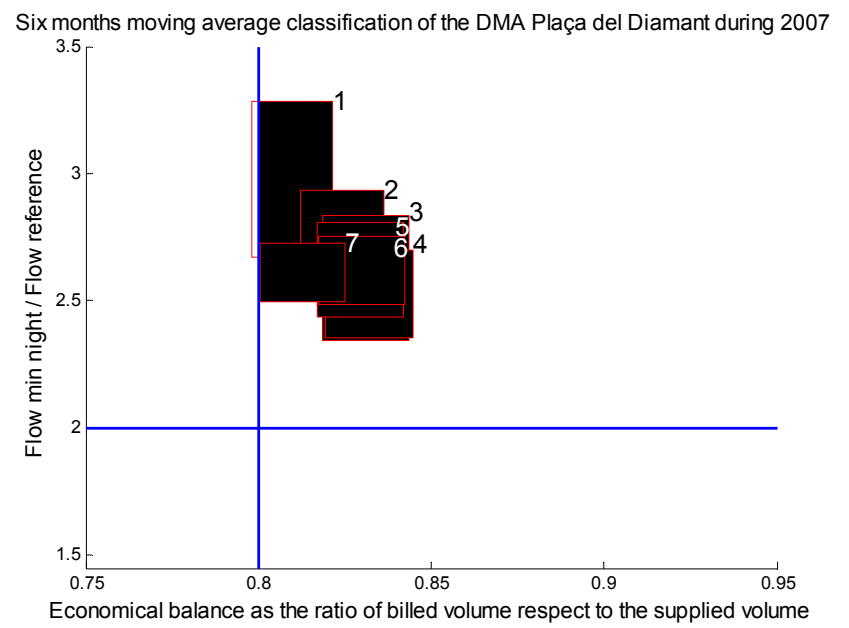

Fig. 10. Results for the water economical balance using a moving average and Qmin/Qref for Plaça del Diamant

\section{CONCLUSIONS}

This paper has introduced a new methodology to detect real water losses in urban water networks with the management of the uncertainties of the flow measurements using interval models. It is based on the combined use of the DMA water balance confidence intervals for a period of time longer than a month (a trimester, semester or year) with an appropriated night flow ratio intervals.
This combined use allows distinguishing between four kinds of situations in a given DMA:

- real water losses.

- apparent water losses,

- $\quad$ high night consumptions, or

- correct situation.

The confidence interval evaluation for the water economical balance of each DMA allows taking into account the data uncertainties. A methodology for the uncertainty calculation is proposed as well based on the statistical study of the flow prediction models. The use of different periods of time has allowed the stabilisation of the diagnosis with reducing the number of diagnosis.

The methodology described in this paper has been illustrated in a DMA of the Barcelona water distribution network using real data. In this example, the Plaça del Diamant sector of Barcelona gives inconclusive diagnoses when nominal monthly water economical balances are used. However, using the proposed methodology that takes into account measurements errors, a unique diagnostic can be easily obtained to detect real water loss in DMAs.

\section{ACKNOLEDGMENTS}

This work has been funded by the Spanish Ministry of Economy and Competitiveness through the CICYT project SHERECS (ref. DPI2011-26243), WATMAN (ref. DPI2009-13744) and by AGBAR company through the PROFURED and RTMN Alliance Projects.

\section{REFERENCES}

Almandoz J., Arregui F., Cabrera E., Cobacho R. (2005). Leakage Assessment through Water Distribution Network Simulation. J. Water R. P. and M., Vol 131, 6, pp. 458-466.

Farley M., Trow S. (2003). Losses in Water Distribution Networks. IWA Publishing.

Lambert A. (1994), Accounting for losses: the Burst and background concept (BABE) IWEM Journal, vol 8(2), 20514.

Lambert A. (2000). Losses from Water Supply Systems: Standard Terminology and Recommended Performance Measures. IWA.

Peralta A., Bosch, E., López, R. (2005) Desarrollo de un método de cálculo del agua consumida en un abastecimiento, AGBAR internal report, July 2005.

R. Pérez, V. Puig, J. Pascual, J. Quevedo, E. Landeros, A. Peralta (2010). Leakage Isolation using Pressure Sensitivity Analysis in Water Distribution Networks: Application to the Barcelona case study. LSS2010. Lille (France).

Quevedo J., J. Blanch, V. Puig, J. Saludes, S. Espín (2009). Methodology to Determine the Drinking Water Transport Network Efficiency based on Interval Computation of Annual Performance. 5th IWA Water Loss. South Africa.

Wu Z., Sage P. (2006) Water Loss Detection via Genetic Algorithm Optimization-Based model Calibration. Annual International Symp. on Water Distribution System Analysis. 